\title{
Management of Keratoacanthoma
}

\author{
Jimmy Alain
}

Published online: 18 April 2012

(C) Springer Science+Business Media, LLC 2012

\begin{abstract}
Keratoacanthoma is a tumor that is seen on a regular basis in a dermatologic and dermato-oncologic practice. The accurate management of this tumor is the biggest challenge. Many treatment options are available. In this review, we summarize the clinical and histological features of this not uncommon tumor. We review the current management with an emphasis on treatment.
\end{abstract}

Keywords Keratoacanthoma · Management · Therapy · Squamous cell carcinoma $\cdot$ Methotrexate $\cdot$ Mohs surgery

\section{Introduction}

Since it was first described in 1889 by Hutchinson [1] and recognized as an entity in the 1950s, keratoacanthoma (KA) has always been a conundrum. The diagnosis of this tumor is always easy to make retrospectively, but clinically it is always a challenge and the clinician must be careful because KA may not behave like one.

\section{Making the Diagnosis}

Keratoacanthoma is a cutaneous tumor that affects elderly patients (commonly in hair-bearing regions and central part of the face) but also middle-aged patients. They often develop on chronic sun-exposed skin but may appear on non-

\footnotetext{
J. Alain $(\bowtie)$

Department of Dermatology, Centre Hospitalier Universitaire de Québec, L'Hôtel-Dieu de Québec, 11, Côte du Palais, Québec City, Qc G1R 2J6, Canada

e-mail: jimmyalain@me.com
}

overexposed skin. They have not been reported on the palms and soles, or mucous surfaces. This tumor erupts rapidly over a few to several weeks. There is a rapid growth (4-6 weeks) and KA can reach $2 \mathrm{~cm}$ within a couple of months. It is capable of auto-resolution. This last point is essential for the diagnosis of this tumor. The clinical regression frequently observed in KA is also an important feature [2••]. It is improbable that invasive squamous cell carcinoma will involute by itself, but this can be established only retrospectively. There has been an ongoing debate since it was first described as to whether keratoacanthoma is or is not a distinct subset of well-differentiated squamous cell carcinoma (SCC) [1, 2••, $3-8,9 \cdot \bullet]$. Some KA has been reported to metastasize, but this unexpected evolution of KA may be the consequence of a SCC that was initially misdiagnosed [7].

The clinical aspect of KA is the other key point. The first evidence of KA is a well-defined, rounded, firmed papule, plaque, or nodule that is flesh colored or reddish. When it was first described, a yellowish aspect was described and it was termed molluscum sebaceum [10]. The epidermis over the nodule is shiny and numerous telangiectasias can be seen just under the surface. The center is made of a keratin-filled crater and may be covered by a crust. Table 1 summarizes the clinical differences between KA and SCC

There are many clinical variants of solitary KA. Two forms, giant keratoacanthoma (GKA) and keratoacanthoma centrifugum marginatum $(\mathrm{KACM})[11 \bullet]$, may attain a large size. Those lesions may grow rapidly and reach a size from $5 \mathrm{~cm}$ up to $20 \mathrm{~cm}$. In GKA, involution occurs after several months, whereas with KACM there is no tendency toward spontaneous regression. Another variant is subunguial and can be seen on the distal portion of a fingernail. This entity rarely shows spontaneous involution.

Others clinical sub-types are worth mentioning. Multiple self-healing squamous epitheliomas (Ferguson-Smith 
Table 1 Clinical features of KA and SCC

\begin{tabular}{llll}
\hline & KA & SCC & Comments \\
\hline Clinical appearance & $\begin{array}{l}\text { Nodule volcano-like } \\
\text { Yellowish aspect }\end{array}$ & $\begin{array}{l}\text { Papule or nodule } \\
\text { Not always keratotic }\end{array}$ & Volcano-like nodule favors KA \\
Course & Rackground of actinic damages & Absence of central crust should favors SCC \\
Rermoscopy & $\begin{array}{l}\text { Regression is the rule } \\
\text { Central ulceration }\end{array}$ & Regression is rare & $\begin{array}{l}\text { Although the rapid onset and growth over weeks } \\
\text { favors KA, SCC may behave in this manner }\end{array}$ \\
& Elongated hairpin blood vessels on & Whitish or reddish pattern \\
a white or yellow background & $\begin{array}{l}\text { Scaly or crusted surface } \\
\text { Polymorphous blood vessels }\end{array}$ & \\
\hline
\end{tabular}

$K A$ keratoacanthoma, $S C C$ squamous cell carcinoma

syndrome) were described in 1930. It is a rare autosomal dominant condition where multiple keratoacanthomas develop. A mutation in the TGFBR1 gene in these patients has been reported [12]. Multiple lesions have also occurred in patients with defective cell-mediated immunity. KA is also a feature of Torre's syndrome, with multiple internal malignancies associated with sebaceous adenoma. Another entity, generalized eruptive keratoacanthoma [13], has also been reported. It particularly affects the face, and the lesions can be confluent. Spontaneous involution of lesions is the rule for this sub-type.

On dermoscopy, classic KA may show an unspecific pattern with a central ulceration with blood crusts. On classical cases, a corona of elongated hairpin blood vessels on a white background corresponding to a white keratotic halo can be seen. Other dermoscopic features of keratoacanthomas are multicomponent pattern, polymorphous vessel, and central keratotic plug. Unfortunately, elongated hairpin blood vessels on a white keratotic halo are non-specific of keratoacanthomas and can be observed in invasive squamous cell carcinomas [14]. In summary, dermoscopy is helpful to comfort ourselves for classical cases where classical clinical features are also present.

\section{Histology and Pathogenesis}

Histologically, the characteristics of KA can be very similar to a well-differentiated SCC $[2 \bullet \bullet, 9 \bullet \bullet$. The tumor has a symmetrical globular form and is localized in the dermis. Usually, the extension is not deeper than the sweat glands. The epidermis becomes thinned as it rises over the tumor. Absence of actinic keratosis surrounding the tumor is often observed. Centrally, a crateriform squamous proliferation with a central core of compact hyperkeratotic is seen [5]. Atypia and atypical mitotic figures can also be seen but are usually limited. Keratinocytes may show glassy and eosinophilic cytoplasm. Neutrophil micro-abscess may be present and is a helpful feature.

Because of the overlap of KA and SCC features, it is a challenge for dermatopathologists to establish diagnosis without any doubt. Regularly, an overlap diagnosis is made ("SCC with KA-like properties" or "KA but invasive SCC cannot be ruled out") and makes treatment decisions difficult. Table 2 summarizes the histologic features of KA.

The pathogenesis is still unclear. It is known that lesions start with hyperplasia of the infundibulum of one or many follicles, but cause is not known. Some studies explored the theory of viral genesis. Some of them found a link between the tumor and HPV sub-types [15], but more studies are needed as results are inconsistent [16].

\section{Management}

KA are well known for their rapid rate of growth but this is also seen with SCC, especially in immunosuppressed patients. Because of spontaneous involution seen in classical cases, a conservative "wait and see" approach after a clear histopathologic diagnosis theoretically could be done. This involution usually happens after 6 months or so [2••]. But because squamous cell carcinoma can masquerade as KA, caution is imperative. Also, because many modalities are available and can be easily performed, it is the rule to offer an active management. Another reason to treat is that regression of KA causes important scarring.

Surgical treatment is the gold standard for KA management. Standard surgical excision $[3,4]$ in the region can be easily done should be performed. If standard excision for KA is the option, it is logical to use the currently recommended surgical margins for SCC (4-6 mm) [17]. Curettage and electrodessication $[18,19]$ is also an interesting modality but the tumor may recur. Mohs surgery is the treatment of choice when tissue sparing is an issue [20]. Also, in solid organ transplant patients (SOTP), KA should be treated by Mohs for two reasons. First, because of high risk of recurrence. The other reason involves the problem of making an accurate diagnosis when a biopsy is performed on KA. In our experience, histological diagnosis of KA is seldom done in SOTP. The histologic features are usually in favor of SCC and treatment is performed consequently. 
Table 2 Histologic features of KA and SCC

\begin{tabular}{|c|c|c|c|}
\hline & Keratoacanthoma & Squamous cell carcinoma & Comments \\
\hline \multirow[t]{8}{*}{ Histologic features } & \multirow[t]{3}{*}{$\begin{array}{l}\text { Horn-filled invagination of the epidermis } \\
\text { Well demarcated (with sharp cutoffs) }\end{array}$} & Often less well demarcated & $\begin{array}{l}\text { Fusiform specimen should be excised for } \\
\text { biopsy (shave biopsy is inadvisable) }\end{array}$ \\
\hline & & $\begin{array}{l}\text { Invasion deeper than sweat } \\
\text { glands may be seen }\end{array}$ & \multirow[t]{7}{*}{$\begin{array}{l}\text { Base of the lesion is mandatory } \\
\text { to establish accurate diagnosis }\end{array}$} \\
\hline & & $\begin{array}{l}\text { Atypical cell with mitotic } \\
\text { figures more numerous }\end{array}$ & \\
\hline & Atypical cell may be seen & \multirow{5}{*}{$\begin{array}{l}\text { Perineural invasions } \\
\text { may be seen }\end{array}$} & \\
\hline & $\begin{array}{l}\text { Eosinophilic and glassy } \\
\text { cytoplasm appearance }\end{array}$ & & \\
\hline & Unusual to be deep to sweat glands & & \\
\hline & Dense infiltrate at the base (neutrophilic) & & \\
\hline & Perineural invasions rarely seen & & \\
\hline
\end{tabular}

Many other treatments have been described. Systemic retinoids [21] may be useful in some situations and could be used in multiple lesions. Intralesional therapies such as intra-lesional methotrexate (IL-MTX) [22-28, 29・•] and 5fluorouracil $[22,30]$ have been used for solitary lesions with various success rates and side effects. In our center we examined retrospectively 46 patients who were treated with IL-MTX [29••]. A complete resolution was achieved in $74 \%$ of patients, requiring an average of 1 to 8 injection sessions. Mean total dosage was $10 \mathrm{mg}$. In this study, we used a 3-cc syringe (25-G needle) and a MTX concentration of $25 \mathrm{mg} / \mathrm{mL}$, which was diluted $1 / 2: 1 / 2$ using in most cases xylocaine $1 \%$ with epinephrine or normal saline in some patients. Xylocaine $1 \%$ with epinephrine is of interest for injection by blanching the lesion and showing presence of the product. Figure 1 demonstrates the technique of injection. IL-MTX is an interesting option for classic KA because it is minimally invasive, well tolerated, and barely

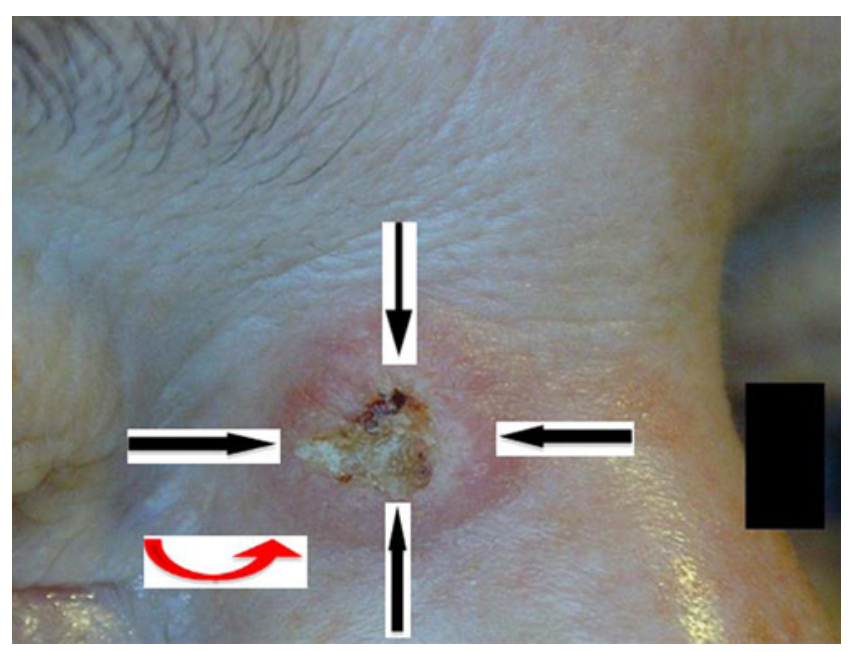

Fig. 1 Technique of injection. Methotrexate is equally injected in the four quadrants of the tumor (black arrows) and in the central deep part of the tumor, underneath of the crater (red arrow) leaves a visible scar. Close follow-up (every $2-4$ weeks) is mandatory so tumor involution may be assessed. Previous case reports conclude that IL-MTX is an effective treatment for some selected KA as well as a minimally invasive procedure $[22,29 \bullet \cdot$. Surgical management should be undergone immediately if there is no response to IL-MTX and the physician must be ready to act accordingly. Other treatment options are rarely used and include radiation [31] and topical imiquimod [32]. Table 3 shows treatment options for KA.

Over the past few years, case reports showed eruption of $\mathrm{KA}$ as a surgical complication $[33,34]$. It may occur on or surrounding previous surgical sites but also at a distant site [35]. Etiology of this phenomenon is obscured. As trauma of the skin is involved in all cases, the hypothesis of viral infection of keratinocytes could be raised and support the viral genesis pathway in this tumor.

\section{Conclusions}

Because of its unforeseeable evolution, keratoacanthoma is a challenging tumor. In the past when accessibility to medical care was difficult, many of these tumors did probably regress without treatment. But in our era, with all possibilities of

Table 3 Treatment options for keratoacanthoma

Standard surgical excision

Curettage and electrodessication or cryosurgery

Mohs micrographic surgery

Intra-lesional methotrexate

Intra-lesional 5-fluorouracil

Systemic retinoids

Radiotherapy

Topical $5 \%$ imiquimod 
treatment, some sort of treatment is mandatory. Surgery remains the gold standard in the treatment of KA. With standard surgical procedures and Mohs micrographic surgery, the vast majority of lesions can be easily treated with more than excellent cure rate [18-20]. For some selected patients (volcano-like papule/nodule should be present with a rapid onset, absence of actinic damage surrounding), MTX could be useful. If histology supports the diagnosis of KA, the utility of IL-MTX is reinforced.

For those patients treated by MTX, close follow-up is required. Clinical regression secondary to IL-MTX can be observed with increasing of the central keratotic crater and decreasing of the tumor size. Accurate measures should be assessed at every visit.

Prognosis of KA is excellent as long it is a KA. Few reports show metastasis. It is probably logical to estimate that those tumors were not real KA but aggressive SCC with some clinical and histologic KA features.

Disclosure No conflicts of interest relevant to this article were reported.

\section{References}

Papers of particular interest, published recently, have been highlighted as:

- Of importance

- Of major importance

1. Hutchinson J. The crateriform ulcer of the face : a form of epithelial cancer. Trans Pathol Soc (London) 1889;40: 275

2. • Ko CJ. Keratoacanthoma: facts and controversies. Clin Dermatol 2010;28(3):254-61. This article reviews the clinical management and treatment options of $K A$.

3. Beham A, Regauer S, Soyer HP, Beham-Schmid C. Keratoacanthoma: a clinically distinct variant of well-differentiated squamous cell carcinoma. Adv Anat Pathol 1998;5:269-80.

4. Manstein CH, Frauenhoffer CJ, Besden JE. Keratoacanthoma: is it a real entity? Ann Plast Surg 1998;40:469-72.

5. Rapini RP. Practical Dermatopathology. Mosby: Elsevier; 2005. p. 247-8.

6. Goldenhersh MA, Olsen TG. Invasive squamous cell carcinoma initially diagnosed as a giant keratoacanthoma. J Am Acad Dermatol 1984;10:372-8.

7. Wilsmann-Theis D, Wenzel J, Betten HH, Kukuk G, Bieber T, Schmid-Wendtner MH. A rapidly growing squamous cell carcinoma or keratoacanthoma or both? Acta Derm Venereol 2007;87 (5):447-8.

8. Cribier B. Keratoacanthoma? Better to say "squamous cell carcinoma, keratoacanthoma type". Ann Dermatol Venereol 2008;135 (8-9):541-6.

9. - Mandrell JC, Santa Cruz D. Keratoacanthoma: hyperplasia, benign neoplasm, or a type of squamous cell carcinoma? Semin Diagn Pathol 2009;26(3):150-63. This article reviews the conundrum of diagnosis of $K A$ and gives a rational opinion on management.

10. Musso L, Gordon H. Spontaneous résolution of molluscum sebaceum. Proc R Soc Med 1950;43 :838.

11. - Ghosh SK, Bandyopadhyay D. Keratoacanthoma centrifugum marginatum: a rare variant of keratoacanthoma. J Cutan Med Surg. 2010;14(1):48-50. This article is a review of a rare but important variant of $K A$.

12. Goudie DR, D'Alessandro M. Multiple self-healing squamous epithelioma is caused by a disease-specific spectrum of mutations in TGFBR1. Nat Genet. 2011 Feb 27;43(4):365-9.

13. Schwartz RA, Błaszczyk M. Generalized eruptive keratoacanthoma of Grzybowski: follow-up of the original description and 50-year retrospect. Dermatology. 2002;205(4):348-52.

14. Robert H. Johr, Dermoscopy: The Essentials. Elsevier Mosby 2004

15. Forslund O, DeAngelis PM. Identification of human papillomavirus in keratoacanthomas. J Cutan Pathol. 2003 Aug;30(7):4239.

16. Viviano E, Sorce M, Mantegna M. Solitary keratoacanthomas in immunocompetent patients: no detection of papillomavirus DNA by polymerase chain reaction. New Microbiol. 2001 Jul;24 (3):295-7.

17. Brodland DG, Zitelli JA, Surgical margins for excision of primary cutaneous squamous cell carcinoma. J Am Acad Dermatol. $1992 ; 27: 241-48$

18. Reymann F. Treatment of keratoacanthomas with curettage. Dermatologica 1997;155:90-6.

19. Nedwich JA. Evaluation of curettage and electrodessication in treatment of keratoacanthoma. Australas J Dermatol 1991;32: $137-41$.

20. Larson PO. Keratoacanthomas treated with Mohs' micrographic surgery: a review of forty-three cases. J Am Acad Dermatol 1987;16:1040-4

21. Wong WY, Kolbusz RV, Goldberg LH, Guana A. Treatment of recurrent keratoacathoma with oral isotretinoin. Int J Dermatol 1994;33:579-83.

22. Melton JL, Nelson BR, Stough DB, Brown MD, Swanson NA, Johnson TM. Treatment of keratoacanthomas with intralesional methotrexate. J Am Acad Dermatol 1991;25:1017-23.

23. Hurst LN, Gan BS. Intralesional methotrexate in keratoacanthoma of the nose. Br J Plast Surg 1995;48:243-6.

24. Cuesta-Romero C, de Grado-Pena J. Intralesional methotrexate in solitary keratoacanthoma. Arch Dermatol 1998;134:513-4.

25. Remling R, Mempel M, Schnopp N, Abeck D, Ring J. Intralesional methotrexate injection: an effective time and cost saving therapy alternative in keratoacanthomas that are difficult to treat surgically. Hautarzt 2000;51:612-4.

26. Spieth K, Gille J, Kaufmann R. Intralesional methotrexate as effective treatment in solitary giant keratoacanthoma of the lower lip. Dermatology 2000;200:317-9.

27. Richard MA, Gachon J, Choux R, Laurans R, Folchetti G, Grob JJ. Treatment of keratoacanthoma with intralesional methotrexate injections. Ann Dermatol Venereol 2000;127:1097.

28. Annest NM, VanBeek MJ, Arpey CJ, Whitaker DC. Intralesional methotrexate treatment for keratoacanthoma tumors: a retrospective study and review of the literature. J Am Acad Dermatol 2007;56:989-93.

29. •- Aubut N, Alain J, Claveau J. Intralesional methotrexate treatment for keratoacanthoma tumors: A retrospective case series. (accepted for publication 2011). This article is a large case series reporting utilities of methotrexate in the treatment of $K A$.

30. Parker CM, Hanke CW. Large keratoacanthomas in difficult locations treated with intralesional 5-fluorouracil. J Am Acad Dermatol 1986;14:770-7.

31. Goldschmidt H, Sherwin WK. Radiation therapy of giant aggressive keratoacanthomas. Arch Dermatol 1993;129:1162-5. 
32. Dendorfer M, Oppel T, Wollenberg A, Prinz JC. Topical treatment with imiquimod may induce regression of facial keratoacanthoma. Eur J Dermatol 2003;13:80-2.

33. Goldberg LH, Silapunt S, Beyrau KK. Keratoacanthoma as a postoperative complication of skin cancer excision. J Am Acad Dermatol. 2004 May;50(5):753-8.
34. Metelitsa AI, Alster TS. Fractionated laser skin resurfacing treatment complications: a review. Dermatol Surg. 2010 Mar;36 (3):299-306.

35. May JT, Patil YJ. Keratoacanthoma-type squamous cell carcinoma developing in a skin graft donor site after tumor extirpation at a distant site. Ear Nose Throat J. 2010 Apr;89(4):E11-3. 